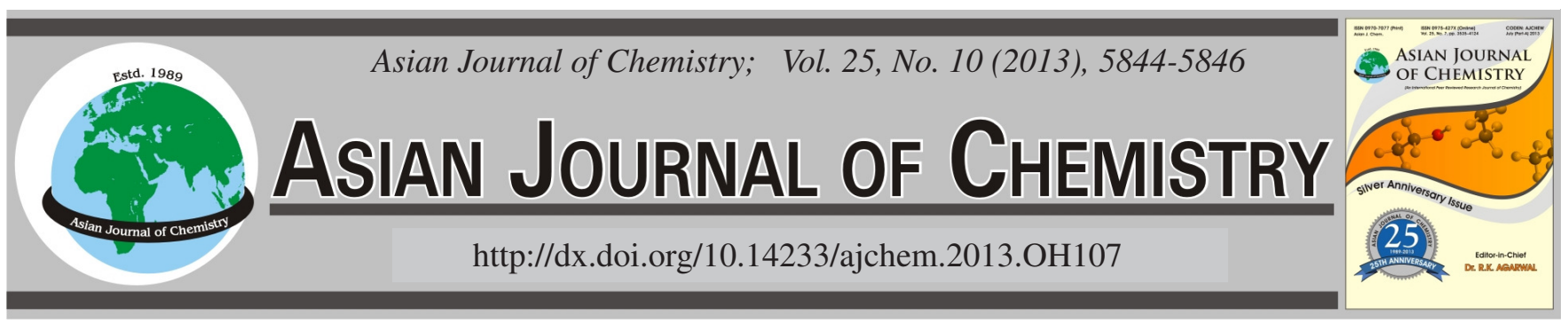

\title{
Synthesis of B-C-N Composite from Melamine-Formaldehyde Resins Containing Boron and Its Electric Double Layer Capacitor Performance $\dagger$
}

\author{
Yasuhiko Arai, Taro Kinumoto, Tomoki Tsumura and Masahiro Toyoda*
}

Department of Applied Chemistry, Faculty of Engineering, Oita University, Oita 870-1192, Japan

*Corresponding author: Fax: +8197 5547904; E-mail: toyoda22@oita-u.ac.jp

Melamine-formaldehyde resin including boron (MFB resin) was prepared from melamine, formaldehyde and boric acid. B-C-N composite was prepared by pyrolysis of its MFB resin at $800-1000{ }^{\circ} \mathrm{C}$ for $1 \mathrm{~h}$ in an inert atmosphere. Nitrogen contents in its B-C-N composite was kept high ratio of N/C, up to 0.24 , in spite of heat treatment temperature. Boron contents depended on the ratio of formaldehyde added. Electric double layer capacitor (EDLC) performance of samples was evaluated in $40 \% \mathrm{H}_{2} \mathrm{SO}_{4}$ aqueous electrolyte by $\mathrm{CV}$ characteristic and galvanostatic charge/discharge measurement using three electrode cell. Electric double layer capacitor performance was as high as $500 \mathrm{~F} / \mathrm{g}\left(1.1 \mathrm{~F} / \mathrm{m}^{2}\right)$. The specific surface area of B-C-N composite obtained is shown $300-600 \mathrm{~m}^{2} / \mathrm{g}$. From the standpoint of specific capacitance per unit surface area, electric double layer capacitor performance increased with increasing N/C and it is shown the correlation between electric double layer capacitor performance and N/C.

Key Words: B-C-N composite, Melamine-formaldehyde resin, Electric double layer capacitor.

\section{INTRODUCTION}

Electric double layer capacitor stores electric charge on interface between electrode and electrolyte. Therefore porous carbon, such as activated carbon, is widely used for commercial electric double layer capacitor electrode because a large surface area promises high energy density. However, increasing surface area is accompanied by increasing pore volume, hence energy density unit per volume is difficult to rise by increasing surface area of carbonous electrode. Accordingly new electrode materials are investigated for super-capacitor. Recently nitrogen enriched carbon materials showed high capacitances in aqueous electrolyte $^{1,2}$. The high capacitance enriched by nitrogen, proposed redox reactions of functional groups containing nitrogen, improving wetness of the pore walls due to the formation of polar functional groups and others ${ }^{3}$. Additionally it is reported that the nitrogen doping into the carbon hexagonal structure causes slight distortion of the hexagonal plane and also imbalanced distribution of the charges on carbon and nitrogen atoms in the plane $e^{4,5}$. Furthermore, boron doping to hexagonal plane makes uneven charge distribution larger than nitrogen doping ${ }^{6}$. Therefore, boron and nitrogen co-doping to carbonous electrode material is expected to enhance electric double layer capacitor performance. It is known that hexagonal boron nitride is synthesized from pyrolyzed melamine diborate.
However, it is difficult to prepare carbonized melamine because melamine is decomposed at low temperature ( $\left.c a .360^{\circ} \mathrm{C}\right) . \mathrm{In}$ this study, melamine-formaldehyde resin including boron (MFB resin) was prepared from melamine, formaldehyde and boric acid. B-C-N composite was prepared by pyrolysis of its MFB resin at $800-1000{ }^{\circ} \mathrm{C}$ for $1 \mathrm{~h}$ in an inert atmosphere. Herein, we report the characteristics of B-C-N composite and their electric double layer capacitor performance.

\section{EXPERIMENTAL}

Melamine, boric acid and $37 \%$ formaldehyde as starting materials were used regent-grade without purify. MFB resin was prepared according to the following procedure. Melamine and boric acid were dissolved in hot water at the molar ratio of melamine/boric acid $=10 / 1$. The mixture was stirred for $0.5 \mathrm{~h}$, then formaldehyde was added to the mixture at the molar ratio of formaldehyde/melamine $(\mathrm{F} / \mathrm{M})=1.3-2.7 / 1$. It was refluxed at $95{ }^{\circ} \mathrm{C}$ until being a clear solution. $1 \mathrm{~mol} / \mathrm{dm}^{3} \mathrm{HCl}$ aqueous solution was added to the clear solution to adjust at $\mathrm{pH}=c a .4$ and polymerization was taken place. It was kept temperature at $95^{\circ} \mathrm{C}$ for $1 \mathrm{~h}$ and dried at $50^{\circ} \mathrm{C}$ in a conventional oven. As comparative study, resin without boric acid (MF resin) was also prepared by same procedure. The resins were heated at $150{ }^{\circ} \mathrm{C} / \mathrm{h}$ to the temperature in a range of $800-1000{ }^{\circ} \mathrm{C}$ and

$†$ Presented to the 6th China-Korea International Conference on Multi-functional Materials and Application, 22-24 November 2012, Daejeon, Korea 
kept for $1 \mathrm{~h}$ at each temperature in nitrogen atmosphere. The products were ground and boiled in water to dissolve borate by-products, filtrated, then dried. Hereafter, formed B-C-N composites are denoted in the order of resin, $\mathrm{F} / \mathrm{M}$ (or plural) and heat-treated temperature (e.g. MFB1.3-1000). Nitrogen gas adsorption was measured at $-196^{\circ} \mathrm{C}$. The isotherms were used to calculate the specific surface area (SSA), micro pore volume (Vmic) and meso pore volume (Vmeso) by $\alpha$ s-SPE method and BJH method. X-ray photoelectron spectroscopy (XPS) was measured for elemental analysis. Binding energies were calibrated by using containment carbon $(\mathrm{C} 1 \mathrm{~s}=284.8$ $\mathrm{eV}$ ). The composites were fabricated to working electrodes by mixing with 10 mass $\%$ acetylene black onto a platinum plate. Electrochemical measurement was performed in $40 \%$ $\mathrm{H}_{2} \mathrm{SO}_{4}$ electrolyte in a three-electrode cell. An $\mathrm{AglAgCl}$ (saturated $\mathrm{KCl}$ solution) electrode and a platinum plate were used as the reference electrode and the counter electrode, respectively. Cyclic voltammetry and charge/discharge measurement (C/D) were performed at $1 \mathrm{mV} / \mathrm{s}$ and $100 \mathrm{~mA} / \mathrm{g}$, respectively.

\section{RESULTS AND DISCUSSION}

Electric double layer capacitor performance of B-C-N composites: Electric double layer capacitor performance of samples was evaluated in $40 \% \mathrm{H}_{2} \mathrm{SO}_{4}$ aqueous electrolyte by cyclic voltammetry characteristic and galvanostatic charge/ discharge measurement using three electrode cell. Cyclic voltammetry characteristic in its $40 \% \mathrm{H}_{2} \mathrm{SO}_{4}$ electrolyte is shown in Fig. 1. It became clear that proton adsorption in cathode side might be predominates without peculiar redox peak in MFB-800 and MFB-1000. Electric double layer capacitor performance was as high as $500 \mathrm{~F} / \mathrm{g}\left(1.1 \mathrm{~F} / \mathrm{m}^{2}\right)$. The other hand, the cyclic voltammetry for MFB1.3-1000 shows the redox peaks at $0.4-0.6 \mathrm{~V}$ caused by functional groups containing oxygen on the carbon surface.

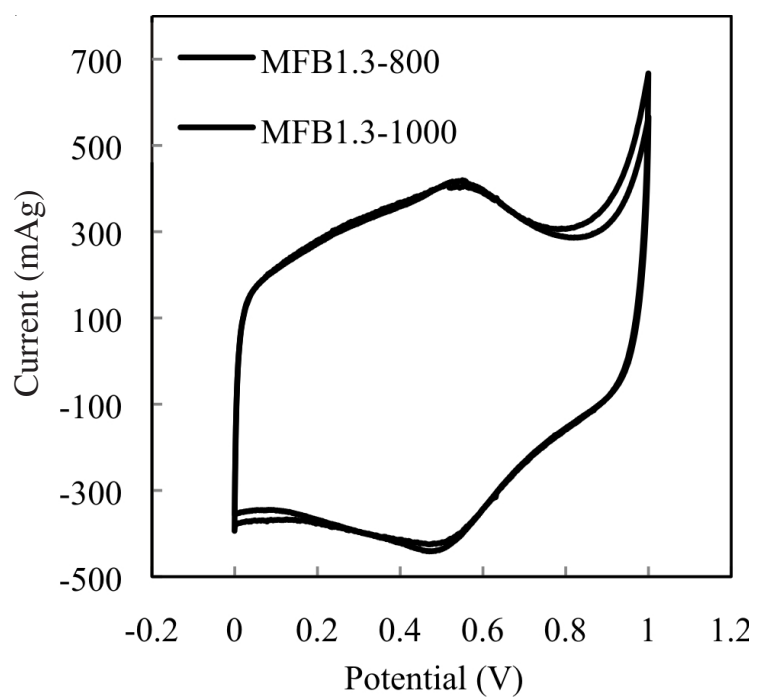

Fig. 1. Cyclic voltamograms of MFB-800 and MFB-1000 in $40 \% \mathrm{H}_{2} \mathrm{SO}_{4}$ electrolyte. Scan rate: $1 \mathrm{mV} / \mathrm{s}$

All carbons heat treated at $800{ }^{\circ} \mathrm{C}$ show high $\mathrm{Cg}$, up to $451 \mathrm{~F} / \mathrm{g}$. However, the $\mathrm{Cg}$ of MFs-1000 decrease, in spite of keeping the SSA. The other hand, the Cg of MFBs-1000 is still high, up to $497 \mathrm{~F} / \mathrm{g}$. It is indicated that the N/C is important factor for the capacitance. The pseudo-capacity caused by redox reaction is also included in the capacitance, but it is smaller than the double layer capacity. Consequently, the Cs plots as function of the N/C for carbonized MFB and MF resin in Fig. 2. It shows the good relation between Cs and N/C. The relation between $\mathrm{Cs}$ and boron content is not recognized, but boron doping to the nitrogen enriched carbon is effective on inhibiting elimination of nitrogen at high temperature.

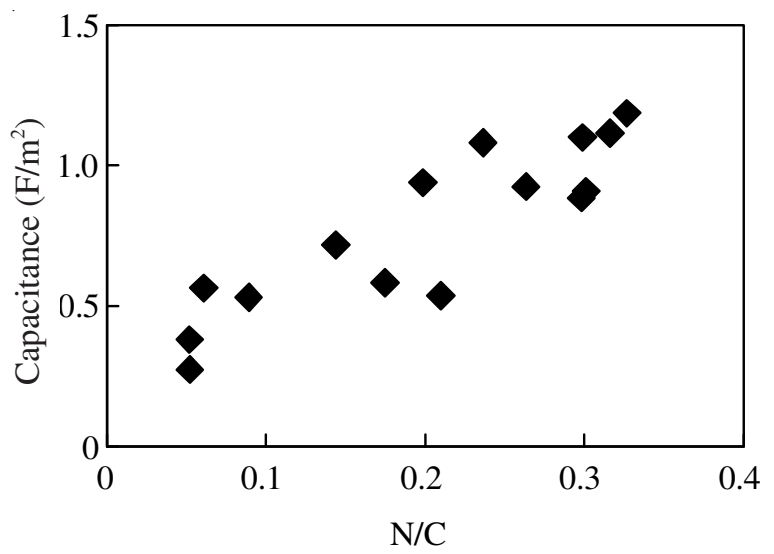

Fig. 2. Cs plots as function of the N/C for carbonized MFB and MF resin

Characterization of B-C-N composites: The chemical composition, nitrogen content (N/C), SSA, Vmic, Vmeso and the specific capacitances unit per weight $(\mathrm{Cg})$ and SSA $(\mathrm{Cs})$ of B-C-N composites are shown in Table-1. N/C of MFBs1000 shows high value than the values of MFs-1000. And N1s spectra of XPS on MFBs-1000 are shown Fig. 3. There are three types of $\mathrm{N}$ component, pyridinic type nitrogen (398.5 \pm $0.2 \mathrm{eV})$, quaternary nitrogen $(401.2 \pm 0.2 \mathrm{eV})$ and $\mathrm{B}-\mathrm{N}$ binding $(398.8 \pm 0.2 \mathrm{eV})$. It is indicated that generating $\mathrm{B}-\mathrm{N}$ bond inhibits elimination of nitrogen at high temperature. There are two types of $\mathrm{N}$ component, pyridinic type and quaternary nitrogen on N1s spectra of MFs-800 and MFs-1000 and differences among the F/M are not recognized. The other hand, N1s spectra of MFBs-1000, especially MFB1.3-1000, indicate generation of quaternary nitrogen is inhibited by boron doping. It is supposed that low F/M lets much melamine borate exist in the resin due to less steric hindrance by methylol as functional groups. B-C-N composites show large SSA around 300$600 \mathrm{~m}^{2} / \mathrm{g}$ without any activation. Comparison pore volume

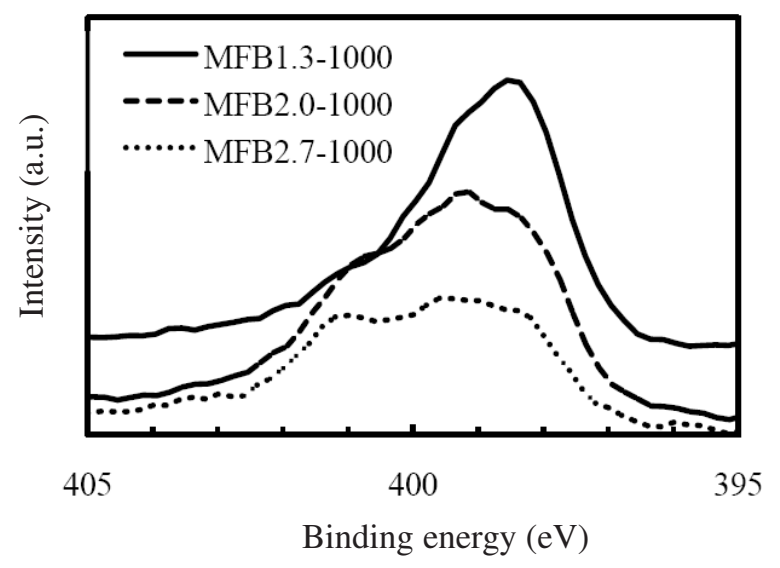

Fig. 3. XPS spectra of N1s on carbonized MFBs-1000 
TABLE-1

CHEMICAL COMPOSITION FROM XPS MEASUREMENT, SURFACE CHARACTERISTICS, CAPACITANCES OF CARBONIZED MFB RESIN

\begin{tabular}{|c|c|c|c|c|c|c|c|c|c|c|}
\hline Sample & $\begin{array}{c}\mathrm{C} 1 \mathrm{~s} \\
(\text { atom \%) }\end{array}$ & $\begin{array}{c}\mathrm{N} 1 \mathrm{~s} \\
(\text { atom \%) }\end{array}$ & $\begin{array}{c}\mathrm{O} 1 \mathrm{~s} \\
(\text { atom \%) }\end{array}$ & $\begin{array}{c}\text { B1s } \\
\text { (atom \%) }\end{array}$ & $\mathrm{N} / \mathrm{C}$ & $\begin{array}{c}\text { SSA } \\
\left(\mathrm{m}^{2} / \mathrm{g}\right)\end{array}$ & $\begin{array}{c}\text { Vmic } \\
(\mathrm{mL} / \mathrm{g})\end{array}$ & $\begin{array}{l}\text { Vmeso } \\
(\mathrm{mL} / \mathrm{g})\end{array}$ & $\begin{array}{c}\mathrm{Cg} \\
(\mathrm{F} / \mathrm{g})\end{array}$ & $\begin{array}{c}\mathrm{Cs} \\
(\mathrm{F} / \mathrm{g}) \\
\end{array}$ \\
\hline MF1.3-800 & 75.3 & 22.5 & 2.2 & - & 0.30 & 280 & 0.13 & 0.40 & 308 & 1.10 \\
\hline MF2.0-800 & 74.1 & 19.5 & 6.4 & - & 0.26 & 330 & 0.15 & 0.23 & 305 & 0.92 \\
\hline MF2.7-800 & 80.1 & 16.8 & 3.1 & - & 0.21 & 560 & 0.25 & 0.13 & 300 & 0.54 \\
\hline MF1.3-1000 & 92.0 & 5.6 & 2.4 & - & 0.06 & 140 & 0.08 & 0.34 & 79 & 0.56 \\
\hline MF2.0-1000 & 92.4 & 4.8 & 2.8 & - & 0.05 & 300 & 0.16 & 0.20 & 114 & 0.38 \\
\hline MF2.7-1000 & 90.3 & 4.7 & 5.0 & - & 0.05 & 530 & 0.25 & 0.21 & 145 & 0.27 \\
\hline MFB1.3-800 & 70.1 & 20.9 & 6.1 & 2.8 & 0.30 & 510 & 0.26 & 0.23 & 451 & 0.88 \\
\hline MFB2.0-800 & 64.9 & 21.2 & 11.7 & 2.2 & 0.33 & 350 & 0.16 & 0.12 & 415 & 1.19 \\
\hline MFB2.7-800 & 69.0 & 21.8 & 7.7 & 1.5 & 0.32 & 320 & 0.16 & 0.15 & 357 & 1.12 \\
\hline MFB1.3-1000 & 66.0 & 15.6 & 8.9 & 9.4 & 0.24 & 460 & 0.26 & 0.54 & 497 & 1.08 \\
\hline MFB2.0-1000 & 78.5 & 11.3 & 6.1 & 4.2 & 0.14 & 300 & 0.16 & 0.34 & 215 & 0.72 \\
\hline MFB2.7-1000 & 84.2 & 7.5 & 5.6 & 2.8 & 0.09 & 600 & 0.29 & 0.16 & 318 & 0.53 \\
\hline
\end{tabular}

between before and after boiling, Vmic after boiling increases a little. However Vmic depends on the resin, because MFs also show micro pore. And $\alpha$ s plot shows f-swing, so micro pore is consisted of ultra micro pore.

\section{Conclusion}

B-C-N composites were synthesized through pyrolysis of MFB resin prepared from the precursor of melamine resin and boric acid. They show large SSA and high N/C in spite of high heat treatment temperature. Their electric double layer capacitor performances were evaluated in $40 \% \mathrm{H}_{2} \mathrm{SO}_{4}$ aqueous electrolyte. Their capacitances are very high, up to $\sim 500 \mathrm{~F} / \mathrm{g}$ $\left(1.1 \mathrm{~F} / \mathrm{m}^{2}\right)$. Especially, the capacitance unit per SSA increases with increasing N/C.

\section{ACKNOWLEDGEMENTS}

The present work was supported by NEDO project on nanotechnolgy.

\section{REFERENCES}

1. M. Kodama, J. Yamashita, Y. Soneda, H. Hatori and K. Kamegawa, Carbon, 45, 1105 (2007).

2. D. Hulicova, J. Yamashita, Y. Soneda, H. Hatori and M. Kodama, Chem. Mater., 17, 1241 (2005).

3. H. Konno, H. Onishi, N. Yoshizawa and K. Azumi, J. Power Sour, 195, 667 (2010).

4. H. Konno, T. Nakahashi and M. Inagaki, Carbon, 35, 669 (1997)

5. M. Inagaki, H. Tachikawa, T. Nakahashi, H. Konno and Y. Hishiyama, Carbon, 36, 1021 (1998).

6. H. Konno, K. Shiba, H. Tachikawa, T. Nakahashi, H. Oka and M. Inagaki, Synth. Met., 125, 189 (2002). 